\title{
Low grade of osteoarthritis development after Latarjet procedure with a minimum 5 years of follow-up: a systematic review and pooled analysis
}

\author{
Alessandra Menon ${ }^{1,2} \cdot$ Chiara Fossati $^{1,2} \cdot$ Mauro Magnani $^{2}$ (D) Sara Boveri ${ }^{4} \cdot$ Riccardo Compagnoni $^{1,2} \cdot$ \\ Pietro Simone Randelli, ${ }^{1,2,3}$
}

Received: 26 May 2021 / Accepted: 7 October 2021 / Published online: 22 October 2021

(c) The Author(s) 2021

\begin{abstract}
Purpose The purpose of this systematic review and pooled analysis was to evaluate incidence and risk factors for glenohumeral osteoarthritis (OA) in patients who underwent Latarjet procedure with a minimum of 5-year follow-up.

Methods The PRISMA guidelines were followed to perform this systematic review. PubMed and EMBASE were searched up to February 29, 2020 for English, human in vivo studies that evaluated glenohumeral OA in patients undergoing Latarjet procedure at least 5 years after surgery. A pooled analysis on the included databases sent by authors was performed to evaluate the risk factors influencing the development or progression of dislocation arthropathy after the Latarjet procedure. Results Four studies, including a total of 280 patients (213 males and 67 females), were analysed. In our study population, the median age at surgery was 25.0 years (range 20.8-32.6 years). and $92.1 \%$ were athletes. In $90 \%$ of the cases, the number of dislocations before surgery were fewer than 5 . The recurrence of instability after Latarjet procedure was observed only in seven patients (2.5\%). The position of the bone graft resulted flush to the anterior glenoid rim in 238 cases (85.3\%), medial in $8(2.9 \%)$ and overhanging in $33(11.8 \%)$. Radiological signs of development or progression of shoulder OA were observed in $25.8 \%$ of the patients, of which $88.6 \%$ presented a grade 1 of OA according to Samilson and Prieto classification. The overhanging position of the bone graft resulted statistically significant for onset or worsening of OA. The age at surgery, the number of dislocations before surgery and the Hill-Sachs lesion were not significantly associated with joint degeneration. Instead, hyperlaxity showed a prevention role in the development of OA after open Latarjet procedure.

Conclusion The Latarjet procedure is a valid and safe surgical treatment in recurrent anterior shoulder instability with a low risk of developing moderate or severe OA also at long-term follow-up. The overhanging position of the bone graft represents the principal risk factor of joint degeneration, whereas the hyperlaxity seems to be protective. Finally, age, gender, time between first dislocation and surgery, and number of dislocations do not seem to affect the onset of OA after Latarjet procedure. Therefore, an accurate execution of the Latarjet procedure can be considered a valid treatment even in young and athletes thanks to the low recurrence rates and the low development of major long-term complications.
\end{abstract}

Level of evidence IV.

Keywords Glenohumeral arthritis $\cdot$ Shoulder arthropathy $\cdot$ Latarjet procedure $\cdot$ Shoulder instability $\cdot$ Dislocation arthropathy $\cdot$ Shoulder osteoarthritis

Mauro Magnani

mauro.magnani1@gmail.com

1 Laboratory of Applied Biomechanics, Department of Biomedical Sciences for Health, Università degli Studi di Milano, Via Mangiagalli 31, 20133 Milan, Italy

2 U.O.C. 1a Clinica Ortopedica, ASST Centro Specialistico Ortopedico Traumatologico Gaetano Pini-CTO, Piazza Cardinal Ferrari 1, 20122 Milan, Italy
3 Research Center for Adult and Pediatric Rheumatic Diseases (RECAP-RD), Department of Biomedical Sciences for Health, Università degli Studi di Milano, Via Mangiagalli 31, 20133 Milan, Italy

4 Scientific Directorate, IRCCS Policlinico San Donato, Piazza Malan 1, 20097 Milan, Italy 


\begin{tabular}{ll}
\multicolumn{2}{l}{ Abbreviations } \\
AP & Anteroposterior \\
HR & Hazard ratios \\
MINORS & Methodological Index for Nonrandomized \\
& Studies \\
n.s. & Non-significant \\
OA & Osteoarthritis \\
PRISMA & $\begin{array}{l}\text { Preferred Reporting Items for Systematic } \\
\end{array}$ \\
Reviews and Meta-Analyses \\
95\% CI & $95 \%$ Confidence intervals
\end{tabular}

\section{Introduction}

Traumatic anterior shoulder dislocation is a common pathology that usually affects competitive-level sporting males between 20 and 30 years old [1,27], with a reported incidence of 24 per 100.000 persons/year [39, 63]. Glenoid and humeral bony defects, in association with soft tissue injuries, often lead to recurrent shoulder instability [12, 15, 29, 57].

The most reliable surgical approach to anterior shoulder instability remains challenging [5, 61]. In clinical practice, anatomical surgeries, such as arthroscopic Bankart repair, represent the best surgical options in patients with no or slight bone loss. The non-anatomical techniques, such as the Latarjet procedure, are preferred in case of glenoid bone loss $>25 \%$ (inverted pear glenoid), significant anteroinferior capsular deficit, patients involved in competitive or contact sports (e.g., rugby), and failed stabilization procedures [7].

In the Latarjet procedure, described for the first time in 1954 [37], the coracoid process along the conjoint tendon is distally transferred and screw fixed to the anterior border of the glenoid. This technique provides shoulder stability with a triple mechanism: restoration of the bone loss provided by the coracoid process, the sling effect created by the dynamic tension on the inferior part of the subscapularis exerted by the conjoint tendon, and, finally, the Bankart effect of capsulolabral repair [45, 62].

Despite excellent long-term results in terms of recurrence rate, the Latarjet procedure shows some complications, including graft malposition and non-union, nerve and vascular injury, hematoma, infection, loss of external rotation, and development of osteoarthritis (OA) [17].

The glenohumeral OA is one of the most feared longterm complications after Latarjet procedure in particular because the patients who underwent this surgery are on average young. Several factors, including advanced age at the first dislocation [36], high number of pre-operative dislocations, contact sports (e.g., rugby and basketball) or heavy manual works (e.g., carpentry and bricklayer), glenoid or humeral head fractures, rotator cuff tears, high-energy trauma and technical errors as bad graft positioning, intraarticular hardware and excessive capsular tightening, have been suggested to increase the risk of $\mathrm{OA}$ in patients who underwent the Latarjet procedure [36, 43]. However, studies with limited evidence and small samples do not allow a definitive conclusion.

The purpose of this study was to perform a systematic review of the literature and conduct the first pooled analysis to establish the incidence and risk factors for long-term glenohumeral OA after a Latarjet procedure in patients with a minimum follow-up of 5 years.

\section{Materials and methods}

A systematic review to identify all studies reporting glenohumeral OA after Latarjet procedure at a minimum follow-up of 5 years was performed. The PRISMA guidelines (Preferred Reporting Items for Systematic Reviews and Meta-Analyses) were followed to perform this systematic review of the literature and to present the results [44]. A protocol was written stating the purpose of the review and the search strategy and registered on PROSPERO (registration ID: CRD42021089462). A flow diagram according to PRISMA guidelines summarizes our selection protocol (Fig. 1).

\section{Primary and secondary outcomes}

Primary and secondary outcomes were planned a priori. The main outcome was the incidence of glenohumeral OA in patients who underwent Latarjet procedure with a minimum of 5 years follow-up. The secondary outcomes included the assessment of the risk factors in developing glenohumeral OA after this surgery.

\section{Search strategy and selection criteria}

An electronic search of the literature was performed in the MEDLINE database via PubMed and Embase database from the databases' inception up to February 29, 2020, using the following search string for title and abstract: (Latarjet OR Coracoid Bone Block) AND \{[(Dislocation Arthropathy) OR (Arthritis)] OR [(Arthrosis) OR (Degenerative Changes)]\}. MeSH terms were used only for "Arthritis".

The search was limited to English literature. Meta-analyses, systematic and narrative reviews, and non-human studies (animal and cadaver studies) were excluded. The search strategy for each specific search is shown in Appendix A.

\section{Study selection}

According to the methodology recommended by Harris et al. [23], after the deletion of duplicates, the title and abstract of 
Fig. 1 Flowchart of the study selection

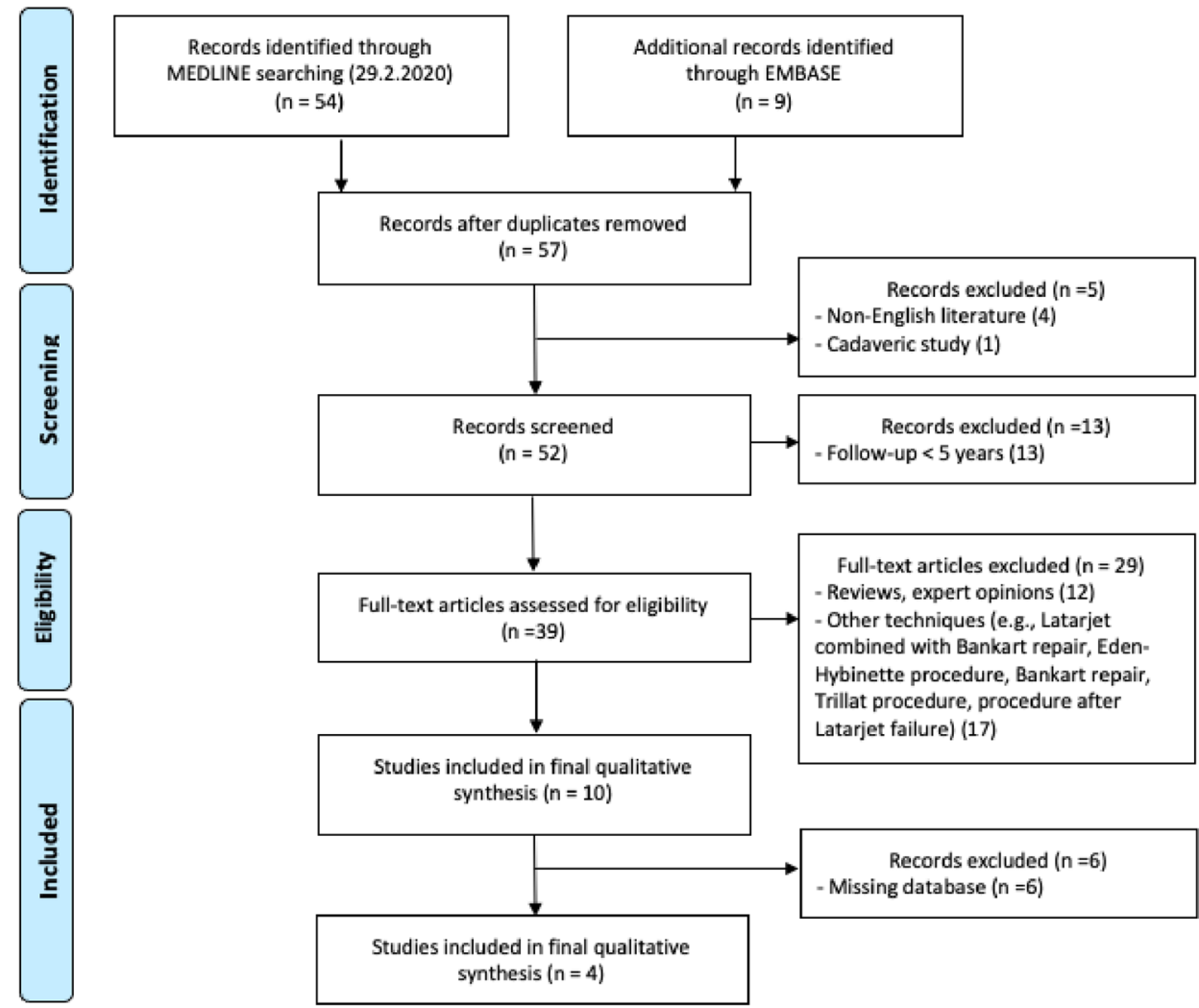

all identified studies were independently examined by two reviewers (C.F., M.M.), who applied the study eligibility criteria. When the title and abstract were pertinent, the article was analysed.

Inclusion criteria were studies in the English that evaluated glenohumeral OA in patients undergoing Latarjet procedure at least 5 years after surgery.

Exclusion criteria were studies not meeting inclusion criteria, studies using different techniques/procedures to manage glenohumeral OA, narrative and systematic reviews, meta-analyses and cadaveric studies.

In case of disagreement between reviewers, researchers obtained the consensus discussing the full text. In case of persistent disagreement, a third reviewer (A.M.) was consulted.

Finally, eligible articles underwent a full-text review for a more detailed evaluation. Both reviewers also manually cross-referenced to ensure that all potential studies were included. Reviewers were not blinded to the authors or affiliated institutions of the retrieved studies. The final list of included studies was agreed to by consensus, and their authors were contacted by email to obtain the raw data. A pooled analysis on the included databases sent by authors was performed to evaluate the risk factors influencing the development or progression of dislocation arthropathy after the Latarjet procedure.

\section{Risk of bias assessment}

Two reviewers (A.M., M.M.) independently assessed methodological quality of the included studies according to the MINORS (Methodological Index for Nonrandomized Studies) checklist [53]. On the base of this tool, 8 items for noncomparative studies and 12 items for comparative studies have been evaluated with a score that varies from 0 to $2(0$ : not reported; 1: reported but inadequate; 2 : reported and adequate). Therefore, the maximum global score was 16 for a non-comparative study and 24 for a comparative study.

The level of evidence of each article was assessed using the 2003 Journal of Bone and Joint Surgery definitions for orthopaedic publications [60].

\section{Data extraction}

Two reviewers (A.M. and C.F.) independently extracted study data using a standardized data extraction form predefined according to the protocol. Discordance was resolved by both reviewers rechecking their extracted data until data sheets corresponded. If no consensus could be reached, a third reviewer (M.M.) was consulted. Authors extracted information regarding the characteristics of the studies (author, year and journal of publication, study design and level of evidence, number of patients and shoulders) and participants (sex, age at surgery and follow-up, dominant 
shoulder or not, follow-up duration, hyperlaxity, sport and physical activity, number of pre-operative dislocations and subluxations, pre-operative validated outcome measures, pre-operative OA according to Samilson and Prieto, preoperative glenoid bone loss/glenoid defect, pre-operative Hill-Sachs lesion, position of graft, graft healing alteration, screw problems), and the clinical, functional and radiographic outcomes of the treatment at the final follow-up (OA according to Samilson and Prieto, validated outcome measures, sport, and physical activity, recurrence of instability, complications and adverse events, recurrence of postrevision instability, number of re-dislocations, satisfaction). Where possible, the compiled data from individual studies were pooled together.

\section{Statistical analysis}

The original datasets of the studies, for which the authors provided us with databases, were analysed. We considered data of survival times subject to right-censoring, for individuals the true survival times exceeded the censoring time. Until the event of interest was not observed precisely, the database had only one follow-up visit after surgery. The approach for analysing interval-censored survival data was the use of nonparametric estimation of the survival function.

The proportional hazards regression model for the interval-censored current time to event data was used to estimate univariate and multivariate hazard ratios (HR) with/and their 95\% confidence intervals ( $95 \% \mathrm{CI}$ ) for evaluating the association between covariates and post-surgery osteoarthritis outcome.

For all analyses, the significance level was set at a $p$ value lower than 0.05 .

Statistical analysis was performed using SAS software, version 9.4 (SAS Institute, Inc., Cary, NC).

\section{Results}

\section{Study selection and study characteristics}

As shown in Fig. 1, a total of 63 references were identified (54 from MEDLINE and 9 from EMBASE). After eliminating duplicates and screening titles and abstracts, 39 were assessed for eligibility. Of these 39 studies, 29 were excluded $[3,4,8-10,14,16,17,19,21,26,28,30-35,38$, 40-42, 46-48, 54, 55, 58, 59]. Ten studies were included in final qualitative synthesis and, finally, six of which $[2,18$, $20,24,25,52]$ were not taken into consideration because the databases were not available. Therefore, 4 studies [11, $36,43,45]$, which included 280 patients who underwent the Latarjet procedure, were analysed. All these analysed
Table 1 Study characteristics

\begin{tabular}{|c|c|c|c|c|}
\hline Study & Year & Design & $\begin{array}{l}\text { Level of } \\
\text { evidence }\end{array}$ & MINORS score \\
\hline Bouju et al. [11] & 2014 & Retrospective & IV & $8 / 16$ \\
\hline $\begin{array}{l}\text { Lädermann et al. } \\
\text { [36] }\end{array}$ & 2013 & Retrospective & III & $10 / 16$ \\
\hline Mizuno et al. [43] & 2014 & Retrospective & IV & $10 / 16$ \\
\hline Neyton et al. [45] & 2012 & Retrospective & IV & $10 / 16$ \\
\hline
\end{tabular}

MINORS Methodological Index for Nonrandomized Studies

studies were retrospective. The mean follow-up was more than 5 years in each of them. The mean MINORS score was 9.5 out of a possible 16 for non-comparative studies (Table 1).

The study population was characterized by general information and clinical data (Table 2). Three out of four studies have even described hyperlaxity [11, 36, 43] and the Hill-Sachs lesion [11, 43, 45].

Each author also evaluated the patients with radiographic protocols, including anteroposterior (AP) and Bernageau views [6]. The AP view was used to assess the presence of glenohumeral OA according to Samilson and Prieto's classification [51]. The Bernageau view was performed to evaluate the position of the bone graft; three positions were described: flush when the graft and the glenoid were in line, medial when the graft was relatively medial to the joint, and, finally, overhanging when the graft was lateral compared to the glenoid joint line. A radiological assessment was performed preoperatively and at the final follow-up to evaluate the joint degeneration in all studies.

\section{Synthesis of results}

The pooled analysis includes 280 patients, of whom 213 males and 67 females. Total characteristics of the study population are included in Table 2 .

The age at surgery was not statistically significant for the appearance or worsening of OA in both univariate and multivariate (respectively, HR $>25$ vs. $\leq 25$ years: 1.56 (95\% CI 0.98-2.49), n.s.) analysis. The same results in univariate analysis were assessed for the number of dislocations before surgery. Moreover, the Hill-Sachs lesion was not significant for the joint degeneration.

Instead, the bone graft position resulted statistically significant in univariate analysis. Compared to flush and medial positions, patients who had an overhanging position of the graft had a statistically significant higher risk of onset or worsening of OA (HR: 4.90 (95\% CI 2.86-8.40), $p<0.001)$. 
Table 2 Characteristics of the study population

\begin{tabular}{|c|c|c|c|c|c|}
\hline & $\begin{array}{l}\text { Overall } \\
(N=280)\end{array}$ & $\begin{array}{l}\text { Bouju } \\
(N=58)\end{array}$ & $\begin{array}{l}\text { Ladermann } \\
(N=117)\end{array}$ & $\begin{array}{l}\text { Mizuno } \\
(N=68)\end{array}$ & $\begin{array}{l}\text { Neyton } \\
(N=37)\end{array}$ \\
\hline Age at surgery in years $(95 \% \mathrm{CI})$ & $25.0(20.8-32.6)$ & $24.4(20.2-35.6)$ & $26.6(21.9-33.7)$ & $24.0(21.0-37.0)$ & $23.0(20.0-27.0)$ \\
\hline $\begin{array}{l}\text { Age at follow-up in years ( } 95 \% \\
\text { CI) }\end{array}$ & $42.0(37.0-49.4)$ & $38.0(32.5-46.0)$ & $44.0(39.0-52.0)$ & $45.0(40.0-54.0)$ & $34.0(30.0-39.0)$ \\
\hline $\begin{array}{l}\text { Length of follow-up in months } \\
(95 \% \mathrm{CI})\end{array}$ & $210.8(199.2-225.1)$ & $152.4(141.1-167.8)$ & $214.7(199.7-243.4)$ & $243.2(237.3-257.7)$ & $174.5(123.9-196.0)$ \\
\hline \multicolumn{6}{|l|}{ Gender $(\%)$} \\
\hline Male & $213(76.1)$ & $40(69.0)$ & $82(70.1)$ & $54(79.4)$ & $37(100)$ \\
\hline Female & $67(23.9)$ & $18(31.0)$ & $35(29.9)$ & $14(20.6)$ & - \\
\hline \multicolumn{6}{|l|}{ Dominancy (\%) } \\
\hline Left & $30(12.6)$ & $5(16.7)$ & $15(13.4)$ & $10(14.7)$ & - \\
\hline Right & $208(87.4)$ & $53(91.4)$ & $97(86.6)$ & $58(85.3)$ & - \\
\hline \multicolumn{6}{|l|}{ Dominancy surgery (\%) } \\
\hline Operated dominant arm & $136(57.1)$ & $39(67.2)$ & $58(51.8)$ & $39(57.4)$ & - \\
\hline No operated dominant arm & $102(42.9)$ & $19(32.8)$ & $54(48.2)$ & $29(42.6)$ & - \\
\hline \multicolumn{6}{|l|}{ Sport pre-op (\%) } \\
\hline Yes & $258(92.1)$ & $58(100)$ & $101(86.3)$ & $62(91.2)$ & $37(100)$ \\
\hline No & $22(7.8)$ & - & $16(13.7)$ & $6(8.8)$ & - \\
\hline \multicolumn{6}{|l|}{ Hyperlaxity (\%) } \\
\hline Yes & $37(15.4)$ & $13(22.4)$ & $20(17.5)$ & $4(5.9)$ & - \\
\hline No & $203(84.6)$ & $45(77.6)$ & $94(82.5)$ & $64(94.1)$ & - \\
\hline \multicolumn{6}{|l|}{ Recurrence of instab (\%) } \\
\hline Yes & $7(2.5)$ & $1(1.7)$ & $2(1.7)$ & $4(5.9)$ & 0 \\
\hline No & $273(97.5)$ & $57(98.3)$ & $115(98.3)$ & $64(94.1)$ & $37(100)$ \\
\hline \multicolumn{6}{|l|}{ OA pre-op (\%) } \\
\hline Yes & $16(5.9)$ & $2(3.5)$ & $3(2.7)$ & $8(11.8)$ & $3(8.1)$ \\
\hline No & $257(94.1)$ & $56(96.5)$ & $107(97.3)$ & $60(88.2)$ & $34(91.9)$ \\
\hline \multicolumn{6}{|l|}{$\begin{array}{l}\text { Grade Samilson and Prieto pre- } \\
\text { op }(\%)\end{array}$} \\
\hline$>1$ & $23(8.2)$ & $2(3.5)$ & $10(8.6)$ & $8(11.8)$ & $3(8.1)$ \\
\hline 0 & $257(91.8)$ & $56(96.6)$ & $107(91.5)$ & $60(88.2)$ & $34(91.9)$ \\
\hline \multicolumn{6}{|l|}{ Glenoid bone loss $(\%)$} \\
\hline 1 & $67(41.1)$ & $20(34.5)$ & - & $20(29.4)$ & $27(73.0)$ \\
\hline 0 & $96(58.9)$ & $38(65.5)$ & - & $48(70.6)$ & $10(27.0)$ \\
\hline \multicolumn{6}{|l|}{ Graft healing (\%) } \\
\hline 1 & $26(9.3)$ & $14(24.1)$ & $7(6.0)$ & $1(1.5)$ & $4(11.1)$ \\
\hline 0 & $254(90.7)$ & $44(75.0)$ & $110(94.0)$ & $67(98.5)$ & $32(88.9)$ \\
\hline \multicolumn{6}{|l|}{ Hill-Sachs (\%) } \\
\hline No or small & $53(32.5)$ & $29(50.0)$ & - & $12(17.6)$ & $12(32.4)$ \\
\hline Mild or large & $110(67.5)$ & $29(50.0)$ & - & $56(83.4)$ & $25(67.6)$ \\
\hline \multicolumn{6}{|l|}{ Number of dislocations (\%) } \\
\hline$\leq 5$ & $252(90.0)$ & $48(82.9)$ & $117(100)$ & $50(73.5)$ & $37(100)$ \\
\hline$>5$ & $28(10.0)$ & $10(17.1)$ & - & $18(26.5)$ & - \\
\hline \multicolumn{6}{|l|}{ Number of subluxations (\%) } \\
\hline$\leq 5$ & $268(95.7)$ & $56(96.6)$ & $117(100)$ & $58(85.3)$ & $37(100)$ \\
\hline$>5$ & $12(4.3)$ & $2(3.4)$ & - & $10(14.7)$ & - \\
\hline \multicolumn{6}{|l|}{ Position of graft coracoid (\%) } \\
\hline Flush & $238(85.3)$ & $51(87.9)$ & $99(85.3)$ & $53(77.9)$ & $35(94.6)$ \\
\hline Medial & $8(2.9)$ & - & - & $7(10.3)$ & $1(2.7)$ \\
\hline Over & $33(11.8)$ & $7(12.1)$ & $17(14.7)$ & $8(11.8)$ & $1(2.7)$ \\
\hline
\end{tabular}


Table 2 (continued)

$\begin{array}{lllll}\begin{array}{l}\text { Overall } \\ (N=280)\end{array} & \begin{array}{l}\text { Bouju } \\ (N=58)\end{array} & \begin{array}{l}\text { Ladermann } \\ (N=117)\end{array} & \begin{array}{l}\text { Mizuno } \\ (N=68)\end{array} & \begin{array}{l}\text { Neyton } \\ (N=37)\end{array}\end{array}$

\begin{tabular}{|c|c|c|c|c|c|}
\hline \multicolumn{6}{|l|}{$\begin{array}{l}\text { Delta of grade Samilson and } \\
\text { Prieto }(\%)\end{array}$} \\
\hline $\begin{array}{l}\text { No difference pre- and post-op } \\
\text { (grade } 0 \text { ) }\end{array}$ & $194(71.3)$ & $53(91.4)$ & $68(61.8)$ & $48(70.6)$ & $25(69.4)$ \\
\hline $\begin{array}{l}\text { No difference pre- and post-op } \\
\text { (grade 1) }\end{array}$ & $8(2.9)$ & $1(1.7)$ & - & $4(5.9)$ & $3(8.3)$ \\
\hline Variation 0 to 1 or 2 or 3 & $62(22.9)$ & $3(5.2)$ & $39(35.5)$ & $12(17.6)$ & $8(22.2)$ \\
\hline Variation 1 to 2 or 3 & $8(2.9)$ & $1(1.7)$ & $3(2.7)$ & $4(5.9)$ & - \\
\hline
\end{tabular}

On the other hand, hyperlaxity showed to be able to significantly prevent $\mathrm{OA}$ after the Latarjet procedure $(\mathrm{HR}=0.31$ (95\% CI 0.11-0.86), $p=0.02$ ) (Table 2). Adjusted multivariate analysis for age at surgery and gender showed no statistical significance for hyperlaxity (HR: 0.38 (95\% CI 0.13-1.10), n.s.) but maintained statistical significance for the overhanging position of the graft (HR: 4.92 (95\% CI 2.75-8.79), $p<0.001$ ) (Table 3).

\section{Discussion}

The most important finding of the present study is that the Latarjet technique exposes patients to relatively moderate risk of developing joint degeneration (25\%), and only in very few patients $(6.4 \%)$, the grade of OA is significant (grade 2 or 3 according to Samilson and Prieto classification). This result has a significant clinical impact, considering that this procedure is usually performed on young and active patients.

This work represents the first systematic review and pooled analysis evaluating the development of glenohumeral OA after the open Latarjet procedure at long-term follow-up. This surgical technique results in good or excellent functional outcomes, with a generally high patient satisfaction (over 90\%) [18, 49] and a great rate of return to sport at preinjury level in athletes (almost 80\%) [50].

The results reported in this study describe a lower incidence of OA than those previously reported by other authors $[13,52]$, probably because of the shorter follow-up. Hovelius et al. [24] found a mild OA in $35.1 \%$ of shoulders and a moderate or severe dislocation arthropathy in $14 \%$ at 15 years of follow-up. Singer et al. [52] in a follow-up study of 20 years, showed $29 \%$ of significant OA (grade 2 or 3 of Samilson and Prieto classification). Chillemi et al. [13], in a 24-years follow-up study, also assessed the presence of OA in $52.5 \%$ of shoulders at the final follow-up (grade 2 or 3 was found in $25 \%$ of the shoulders, according to Samilson and Prieto classification). Despite these signs of joint degeneration, all these authors described good-to-excellent results and high level of satisfaction among their patients.
A recent systematic review [28], which analysed studies with a follow-up of at least 10 years, assessed a development of OA at the final follow-up (mean 16.6 years) in $38.7 \%$ of overall shoulders $(26.5 \%$ with grade 1 of Samilson and Prieto classification, $6.1 \%$ with grade 2 and, finally, $6.1 \%$ with grade 3 ).

However, glenohumeral OA is a common complication also after anatomic shoulder stabilization procedures, such as arthroscopic Bankart repair. A systematic review [22] demonstrated postoperative OA in $26 \%$ of shoulders that underwent arthroscopic Bankart repair with suture anchors with a minimum 5 years of follow-up. Considering the risk of developing shoulder OA in both open Latarjet procedure and arthroscopic Bankart repair [25], we support the theory of other authors [20, 24, 52] who consider dislocation arthropathy to be a part of the natural history of shoulder dislocation.

Moreover, a recent meta-analysis [56] even showed that Latarjet procedure provides a lower degree of OA compared to the other treatments, both operative and non-operative.

Risk factors influencing the development or progression of dislocation arthropathy after Latarjet procedure were evaluated with a pooled analysis.

In this analysis, the only statistically significant factor associated with the development of shoulder OA is the overhanging position of the bone graft, as already reported by other authors [2, 18, 43, 45]. For this reason, the surgeons' experience and proper training for the open Latarjet procedure are necessary to guarantee an appropriate position of the bone graft and minimize the risk of overhanging. Other risk factors, such as the young age at dislocation, the number of dislocations before surgery, and the practice of sport before and after surgery, indicated by several authors [2, 11, $13,20,24,36,43]$ as responsible for the development of shoulder OA, have not been confirmed in this study.

On the other hand, the results of the present study show that hyperlaxity is a protective factor for dislocation arthropathy. Lädermann et al. [36] described similar results, supposing this protection should be given by decreasing 
Table 3 Hazard ratio (HR) and 95\% confidence intervals (CI $95 \%$ ) adjusted for sites

\begin{tabular}{|c|c|c|c|c|}
\hline & \multicolumn{4}{|l|}{ HR (CI 95\%) } \\
\hline & Univariate & $p$ value & Multivariate & $p$ value \\
\hline \multicolumn{5}{|c|}{ Age to surgery in years } \\
\hline$\leq 25$ & Ref & & & \\
\hline$>25$ & $1.56(0.98-2.49)$ & n.s & $1.56(0.91-2.69)$ & n.s \\
\hline \multicolumn{5}{|l|}{ Gender } \\
\hline Female & Ref & & & \\
\hline Male & $1.29(0.73-2.28)$ & n.s & $1.19(0.64-2.20)$ & n.s \\
\hline \multicolumn{5}{|l|}{ Dominancy } \\
\hline Left & Ref & & & \\
\hline Right & $0.78(0.47-1.29)$ & n.s & & \\
\hline \multicolumn{5}{|l|}{ Hyperlaxity } \\
\hline No & Ref & & & \\
\hline Yes & $0.31(0.11-0.86)$ & 0.02 & $0.38(0.13-1.10)$ & n.s \\
\hline \multicolumn{5}{|c|}{ Recurrence of instability } \\
\hline No & Ref & & & \\
\hline Yes & $1.03(0.24-4.30)$ & n.s & & \\
\hline \multicolumn{5}{|c|}{ Glenoid bone loss } \\
\hline 0 & Ref & & & \\
\hline 1 & $1.95(0.96-3.98)$ & n.s & & \\
\hline \multicolumn{5}{|l|}{ Grade healing } \\
\hline 0 & Ref & & & \\
\hline 1 & $1.13(0.48-2.67)$ & n.s & & \\
\hline \multicolumn{5}{|l|}{ Sport post-op } \\
\hline No & Ref & & & \\
\hline Yes & $0.42(0.10-1.74)$ & n.s & & \\
\hline \multicolumn{5}{|l|}{ Hill-Sachs } \\
\hline No & Ref & & & \\
\hline Yes & $1.58(0.64-3.91)$ & n.s & & \\
\hline \multicolumn{5}{|l|}{ Dominancy } \\
\hline No operated & Ref & & & \\
\hline Operated & $0.78(0.47-1.29)$ & n.s & & \\
\hline \multicolumn{5}{|c|}{ Number of dislocations } \\
\hline$\leq 5$ & Ref & & & \\
\hline$>5$ & $0.96(0.38-2.43)$ & n.s & & \\
\hline \multicolumn{5}{|c|}{ Number of subluxations } \\
\hline$\leq 5$ & Ref & & & \\
\hline$>5$ & $1.51(0.51-4.50)$ & n.s & & \\
\hline \multicolumn{5}{|l|}{ Position of graft } \\
\hline Small/Medial & Ref & & & \\
\hline Over & $4.90(2.86-8.40)$ & $<0.001$ & $4.92(2.75-8.79)$ & $<0.001$ \\
\hline
\end{tabular}

postoperative contact pressure between the humeral head and glenoid surface.

The principal strength of this study is the study design. The pooled analysis has allowed analysing many patients from different studies who underwent the open Latarjet technique. The availability of raw data has also permitted the comparison of the information among four different studies to minimize data interpretation errors.
Minor variations in surgical technique introduced by surgeons, different lengths of follow-up, and some missing data in the study population represent the limitations of this study. Additionally, all of the included studies were retrospective. 


\section{Conclusion}

The Latarjet procedure is a valid and safe surgical treatment in recurrent anterior shoulder instability with a low risk of developing moderate or severe OA also at longterm follow-up. The overhanging position of the bone graft represents the principal risk factor of joint degeneration, whereas the hyperlaxity seems to be protective.

Finally, age, gender, time between first dislocation and surgery, and number of dislocations do not seem to affect the onset of OA after Latarjet procedure.

Therefore, an accurate execution of the Latarjet procedure can be considered a valid treatment even in young and athletes thanks to the low recurrence rates and the low development of major long-term complications.

Supplementary Information The online version contains supplementary material available at https://doi.org/10.1007/s00167-021-06771-w.

Acknowledgements The authors thank L. Neyton (Centre Orhopédique Santy, Lyon, France), N. Mizuno (Department of Orthopaedic Surgery, Toyonaka Municipal Hospital, Osaka, Japan), A. Lâdermann (Division of Orthopaedics and Trauma Surgery, Geneve, Switzerland) and Y. Bouju (HRU de Tours, Hôpital Trousseau, Service de Chirurgie Orthopédique et Traumatologique, Tours, France) for providing us with their complete data set.

Author contributions $\mathrm{AM}$ and $\mathrm{CF}$ contributed equally to this work. They carried out the structuring of methodology and formulation of the aims of this study, they provided the raw data with which the analysis was made and carried out the data management; finally, they coordinated the authors during the execution of the paper. MM cooperated in data management and structuring the methodology of the paper, he also drafted the text of this manuscript. SB performed the statistical analysis of the data. RC cooperated in structuring the methodology and formulation of the aims of this study and provided the final revision of the manuscript. PSR supervised the entire execution of this work and provided the final revision of the manuscript.

Funding Open access funding provided by Università degli Studi di Milano within the CRUI-CARE Agreement. No internal or external funding sources were utilized in this investigation.

\section{Declarations}

Conflict of interest Alessandra Menon, Chiara Fossati, Mauro Magnani, Sara Boveri, Riccardo Compagnoni: The authors, their immediate families, and any research foundation with which they are affiliated have not received any financial payments or other benefits from any commercial entity related to the subject of this article. Pietro Simone Randelli: The author is consultant for DePuy, Arthrex, Microport, Medacta. The author, their immediate familiy, and any research foundation with which they are affiliated have not received any financial payments or other benefits from any commercial entity related to the subject of this article.

Ethical approval This article does not contain any studies with human or animals performed by any of the authors.
Open Access This article is licensed under a Creative Commons Attribution 4.0 International License, which permits use, sharing, adaptation, distribution and reproduction in any medium or format, as long as you give appropriate credit to the original author(s) and the source, provide a link to the Creative Commons licence, and indicate if changes were made. The images or other third party material in this article are included in the article's Creative Commons licence, unless indicated otherwise in a credit line to the material. If material is not included in the article's Creative Commons licence and your intended use is not permitted by statutory regulation or exceeds the permitted use, you will need to obtain permission directly from the copyright holder. To view a copy of this licence, visit http://creativecommons.org/licenses/by/4.0/.

\section{References}

1. Abdul-Rassoul H, Galvin J, Curry E, Simon J, Li X (2019) Return to sport after surgical treatment for anterior shoulder instability: a systematic review. Am J Sports Med 47:1507-1515

2. Allain J, Goutallier D, Glorion C (1998) Long-term results of the latarjet procedure for the treatment of anterior instability of the shoulder. J Bone Joint Surg Am 80:841-852

3. Atalar AC, Bilsel K, Eren I, Çelik D, Çil H, Demirhan M (2013) Modified Latarjet procedure for patients with glenoid bone defect accompanied with anterior shoulder instability. Acta Orthop Traumatol Turc 47:393-399

4. Barber FA, Howard MS (2020) Editorial commentary: glenoid track instability management score or instability severity index score - will this decrease Latarjet abuse? Arthroscopy 36:68-70

5. Barlow J, Grosel T, Higgins J, Everhart J, Magnussen R (2019) Surgical treatment outcomes after primary vs recurrent anterior shoulder instability. J Clin Orthop Trauma 10:222-230

6. Bernageau J, Patte D, Debeyre J, Ferrane J (1976) Value of the glenoid profil in recurrent luxations of the shoulder. Rev Chir Orthop Reparatrice Appar Mot 62:142-147

7. Bessiere C, Trojani C, Pélégri C, Carles M, Boileau P (2013) Coracoid bone block versus arthroscopic Bankart repair: a comparative paired study with 5-year follow-up. Orthop Traumatol Surg Res 99:123-130

8. Boileau P, Fourati E, Bicknell R (2012) Neer modification of open Bankart procedure: what are the rates of recurrent instability, functional outcome, and arthritis? Clin Orthop Relat Res 470:2554-2560

9. Boileau P, Richou J, Lisai A, Chuinard C, Bicknell RT (2009) The role of arthroscopy in revision of failed open anterior stabilization of the shoulder. Arthroscopy 25:1075-1084

10. Boileau P, Thélu CÉ, Mercier N, Ohl X, Houghton-Clemmey R, Carles M, Trojani C (2014) Arthroscopic Bristow-Latarjet combined with Bankart repair restores shoulder stability in patients with glenoid bone loss. Clin Orthop Relat Res 472:2413-2424

11. Bouju Y, Gadéa F, Stanovici J, Moubarak H, Favard L (2014) Shoulder stabilization by modified Latarjet-Patte procedure: results at a minimum 10years' follow-up, and role in the prevention of osteoarthritis. Orthop Traumatol Surg Res 100:S213-S218

12. Cavalier M, Johnston T, Tran L, Gauci M, Boileau P (2021) Glenoid erosion is a risk factor for recurrent instability after HillSachs remplissage. Bone Joint J 103-B:718-724

13. Chillemi C, Guerrisi M, Paglialunga C, Salate Santone F, Osimani M (2020) Latarjet procedure for anterior shoulder instability: a 24-year follow-up study. Arch Orthop Trauma Surg 141:189-196 
14. Collin P, Lädermann A (2018) Dynamic anterior stabilization using the long head of the biceps for anteroinferior glenohumeral instability. Arthrosc Tech 7:e39-e44

15. Dekker T, Peebles L, Bernhardson A, Rosenberg S, Murphy C, Golijanin P, Provencher M (2020) Risk factors for recurrence after arthroscopic instability repair-the importance of glenoid bone loss $>15 \%$, patient age, and duration of symptoms: a matched cohort analysis. Am J Sports Med 48:3036-3041

16. Domos P, Chelli M, Lunini E, Ascione F, Bercik MJ, Neyton L, Godeneche A, Walch G (2020) Clinical and radiographic outcomes of the open Latarjet procedure in skeletally immature patients. J Shoulder Elbow Surg 29:1206-1213

17. Domos P, Lunini E, Walch G (2018) Contraindications and complications of the Latarjet procedure. Shoulder Elbow 10:15-24

18. Ernstbrunner L, Wartmann L, Zimmermann SM, Schenk P, Gerber C, Wieser K (2019) Long-term results of the open latarjet procedure for recurrent anterior shoulder instability in patients older than 40 years. Am J Sports Med 47:3057-3064

19. Frank RM, Mellano C, Shin JJ, Feldheim TF, Mascarenhas R, Yanke AB, Cole BJ, Nicholson GP, Romeo AA, Verma NN (2015) Clinical outcomes following revision anterior shoulder stabilization: arthroscopic revision stabilization versus latarjet. Orthop J Sports Med 3:1

20. Gordins V, Hovelius L, Sandström B, Rahme H, Bergström U (2015) Risk of arthropathy after the Bristow-Latarjet repair: a radiologic and clinical thirty-three to thirty-five years of follow-up of thirty-one shoulders. J Shoulder Elbow Surg 24:691-699

21. Gupta A, Delaney R, Petkin K, Lafosse L (2015) Complications of the Latarjet procedure. Curr Rev Musculoskelet Med 8:59-66

22. Harris JD, Gupta AK, Mall NA, Abrams GD, McCormick FM, Cole BJ, Bach BR, Romeo AA, Verma NN (2013) Long-term outcomes after bankart shoulder stabilization. Arthroscopy 29:920-933

23. Harris JD, Quatman CE, Manring MM, Siston RA, Flanigan DC (2014) How to write a systematic review. Am J Sports Med 42:2761-2768

24. Hovelius LK, Sandström BC, Saebö M (2006) One hundred eighteen Bristow-Latarjet repairs for recurrent anterior dislocation of the shoulder prospectively followed for fifteen years: Study IIthe evolution of dislocation arthropathy. J Shoulder Elbow Surg 15:279-289

25. Hovelius LK, Sandström BC, Rösmark DL, Saebö M, Sundgren KH, Malmqvist BG (2001) Long-term results with the Bankart and Bristow-Latarjet procedures: recurrent shoulder instability and arthropathy. J Shoulder Elbow Surg 10:445-452

26. Huguet D, Pietu G, Bresson C, Potaux F, Letenneur J (1996) Anterior instability of the shoulder in athletes: apropos of 51 cases of stabilization using the Latarjet-Patte intervention. Acta Orthop Belg 62:200-206

27. Hurley E, Manjunath A, Bloom D, Pauzenberger L, Mullett H, Alaia M, Strauss E (2020) Arthroscopic Bankart repair versus conservative management for first-time traumatic anterior shoulder instability: a systematic review and meta-analysis. Arthroscopy $36: 2526-2532$

28. Hurley E, Jamal MS, Ali ZS, Montgomery C, Pauzenberger L, Mullett H (2019) Long-term outcomes of the Latarjet procedure for anterior shoulder instability: a systematic review of studies at 10-year follow-up. J Shoulder Elbow Surg 28:e33-e39

29. Itoi E, Lee SB, Berglund LJ, Berge LL, An KN (2000) The effect of a glenoid defect on anteroinferior stability of the shoulder after Bankart repair: a cadaveric study. J Bone Joint Surg Am 82:35-46

30. Karataglis D, Agathangelidis F (2017) Long term outcomes of arthroscopic shoulder instability surgery. Open Orthop J $11: 133-139$
31. Kee YM, Kim HJ, Kim JY, Rhee YG (2017) Glenohumeral arthritis after Latarjet procedure: progression and it's clinical significance. J Orthop Sci 22:846-851

32. Kenesi C, Grelier JL (1990) [Surgical Treatment of Anterior Instability of the Shoulder Using an Anteglenoid Stop] Chirurgie 609-612

33. Knapik DM, Gillespie RJ, Salata MJ, Voos JE (2017) Prevalence and impact of glenoid augmentation in American football athletes participating in the national football league scouting combine. Orthop J Sports Med 5:2325967117722945

34. de I'Eescalopier N, Barbier O, Demoures T, Ollat D, Versier $\mathrm{G}$ (2018) Long-term results of a monocentric series of soldiers after latarjet procedure for anterior shoulder instability. implications for the assessment of soldiers' medical ability. Mil Med 183:e134-e137

35. Lacheta L, Siebenlist S, Imhoff AB, Willinger L (2018) Recurrent instability and instability arthropathy. Unfallchirurg 121:142-151

36. Lädermann A, Lubbeke A, Stern R, Cunningham G, Bellotti V, Gazielly DF (2013) Risk factors for dislocation arthropathy after Latarjet procedure: a long-term study. Int Orthop 37:1093-1098

37. Latarjet M (1954) Treatment of recurrent dislocation of the shoulder. Lyon Chir 49:994-997

38. Lavoué V, Gendre P, Saliken D, Brassac A, Boileau P (2019) The role of arthroscopic soft tissue reconstruction for failed BristowLatarjet procedure. Arthroscopy 35:2581-2588

39. Leroux T, Wasserstein D, Veillette C, Khoshbin A, Henry P, Chahala J, Austin P, Mahomed N, Ogilvie-Harris D (2014) Epidemiology of primary anterior shoulder dislocation requiring closed reduction in Ontario, Canada. Am J Sports Med 42:442-450

40. Li X, Cusano A, Eichinger J (2017) Eden-Hybinette and pectoralis major transfer for recurrent shoulder instability due to failed latarjet and chronic subscapularis rupture. Orthopedics 40:e182-e187

41. Longo UG, Loppini M, Rizzello G, Ciuffreda M, Maffulli N, Denaro V (2014) Latarjet, Bristow, and Eden-Hybinette procedures for anterior shoulder dislocation: systematic review and quantitative synthesis of the literature. Arthroscopy 30:1184-1211

42. Lunn JV, Castellano-Rosa J, Walch G (2008) Recurrent anterior dislocation after the Latarjet procedure: outcome after revision using a modified Eden-Hybinette operation. J Shoulder Elbow Surg 17:744-750

43. Mizuno N, Denard PJ, Raiss P, Melis B, Walch G (2014) Longterm results of the Latarjet procedure for anterior instability of the shoulder. J Shoulder Elbow Surg 23:1691-1699

44. Moher D, Shamseer L, Clarke M, Ghersi D, Liberati A, Petticrew M, Shekelle P, Stewart LA, PRISMA-P Group (2016) Preferred reporting items for systematic review and meta-analysis protocols (PRISMA-P) 2015 statement. Syst Rev 20:148-160

45. Neyton L, Young A, Dawidziak B, Visona E, Hager J-P, Fournier Y, Walch G (2012) Surgical treatment of anterior instability in rugby union players: clinical and radiographic results of the Latarjet-Patte procedure with minimum 5-year follow-up. J Shoulder Elbow Surg 21:1721-1727

46. Nourissat G, Nedellec G, O'Sullivan NA, Debet-Mejean A, Dumontier C, Sautet A, Doursounian L (2006) Mini-open arthroscopically assisted Bristow-Latarjet procedure for the treatment of patients with anterior shoulder instability: a Cadaver study. Arthroscopy 22:1113-1118

47. Reider B (2020) Placing the Latarjet in context. Am J Sports Med 48:17-20

48. Rollick NC, Ono Y, Kurji HM, Nelson AA, Boorman RS, Thornton GM, Lo IK (2017) Long-term outcomes of the Bankart and Latarjet repairs: a systematic review. Open access J Sports Med 8:97-105

49. Rossi L, Tanoira I, Gorodischer T, Pasqualini I, Ranalletta M (2021) Recurrence and revision rates with arthroscopic Bankart 
repair compared with the Latarjet procedure in competitive Rugby players with glenohumeral instability and a glenoid bone loss. Am J Sports Med 49:866-872

50. Rossi L, Tanoira I, Gorodischer T, Pasqualini I, Ranalletta M (2020) Similar results in return to sports, recurrences, and healing rates between the classic and congruent-arc Latarjet for athletes with recurrent glenohumeral instability and a failed stabilization. Arthroscopy 36:2367-2376

51. Samilson RL, Prieto V (1983) Dislocation arthropathy of the shoulder. J Bone Joint Surg Am 65:456-460

52. Singer GC, Kirkland PM, Emery RJH (1995) Coracoid transposition for recurrent anterior instability of the shoulder. A 20-year follow-up study. J Bone Joint Surg Br 77:73-76

53. Slim K, Nini E, Forestier D, Kwiatkowski F, Panis Y, Chipponi J (2003) Methodological index for non-randomized studies (Minors): development and validation of a new instrument. ANZ J Surg 73:712-716

54. Smith CR, Yoon JT, Long JR, Friedman MV, Hillen TJ, Stensby JD (2018) The radiologist's primer to imaging the noncuff, nonlabral postoperative shoulder. Radiographics 38:149-168

55. Spoor AB, De Waal MJ (2005) Long-term results and arthropathy following the modified Bristow-Latarjet procedure. Int Orthop 29:265-267

56. Verweij L, Pruijssen E, Kerkhoffs G, Blankevoort L, Sierevelt I, van Deurzen D, van den Bekerom M (2021) Treatment type may influence degree of post-dislocation shoulder osteoarthritis: a systematic review and meta-analysis. Knee Surg Sports Traumatol Arthrosc 29:2312-2324

57. Villatte G, Martins A, Erivan R, Pereira B, Descamps S, Boisgard $S$ (2020) Use of allograft to reconstruct anterior bony glenoid defect in chronic glenohumeral instability: a systematic review. Arch Orthop Trauma Surg 140:1475-1485

58. Waterman BR, Kilcoyne KG, Parada SA, Eichinger JK (2017) Prevention and management of post-instability glenohumeral arthropathy. World J Orthop 8:229-241

59. Willemot L, De Boey S, Van Tongel A, Declercq G, De Wilde L, Verborgt O (2019) Analysis of failures after the BristowLatarjet procedure for recurrent shoulder instability. Int Orthop 43:1899-1907

60. Wright JG, Swiontkowski MF, Heckman JD (2003) Introducing levels of evidence to the journal. J Bone Joint Surg Am 85:1-3

61. Xu Y, Wu K, Ma Q, Zhang L, Zhang Y, Xu W, Guo JJ (2019) Comparison of clinical and patient-reported outcomes of three procedures for recurrent anterior shoulder instability: arthroscopic Bankart repair, capsular shift, and open Latarjet. J Orthop Surg $14: 326$

62. Yamamoto N, Muraki T, An K, Sperling J, Cofield R, Itoi E, Walch G, Steinmann S (2013) The stabilizing mechanism of the Latarjet procedure: a cadaveric study. J Bone Joint Surg Am 95:1390-1397

63. Zacchilli MA, Owens BD (2010) Epidemiology of shoulder dislocations presenting to emergency departments in the United States. J Bone Joint Surg Am 92:542-549

Publisher's Note Springer Nature remains neutral with regard to jurisdictional claims in published maps and institutional affiliations. 